\title{
Frontières
}

\section{RAIMBAUlt, Ginette, Parlons du deuil, Paris, Payot, 2004,}

$142 \mathrm{p}$.

\section{Jean-Jacques Lavoie}

Volume 17, numéro 2, printemps 2005

URI : https://id.erudit.org/iderudit/1073502ar

DOI : https://doi.org/10.7202/1073502ar

Aller au sommaire du numéro

Éditeur(s)

Université du Québec à Montréal

ISSN

1180-3479 (imprimé)

1916-0976 (numérique)

Découvrir la revue

Citer ce compte rendu

Lavoie, J.-J. (2005). Compte rendu de [RAIMBAULT, Ginette, Parlons du deuil, Paris, Payot, 2004, 142 p.] Frontières, 17(2), 102-103.

https://doi.org/10.7202/1073502ar

Ce document est protégé par la loi sur le droit d'auteur. L'utilisation des services d'Érudit (y compris la reproduction) est assujettie à sa politique d'utilisation que vous pouvez consulter en ligne.

https://apropos.erudit.org/fr/usagers/politique-dutilisation/
Cet article est diffusé et préservé par Érudit.

Érudit est un consortium interuniversitaire sans but lucratif composé de l’Université de Montréal, l'Université Laval et l'Université du Québec à Montréal. Il a pour mission la promotion et la valorisation de la recherche. https://www.erudit.org/fr/ 
RAIMBAULT, Ginette

Parlons du deuil

Paris, Payot, 2004, 142 p.

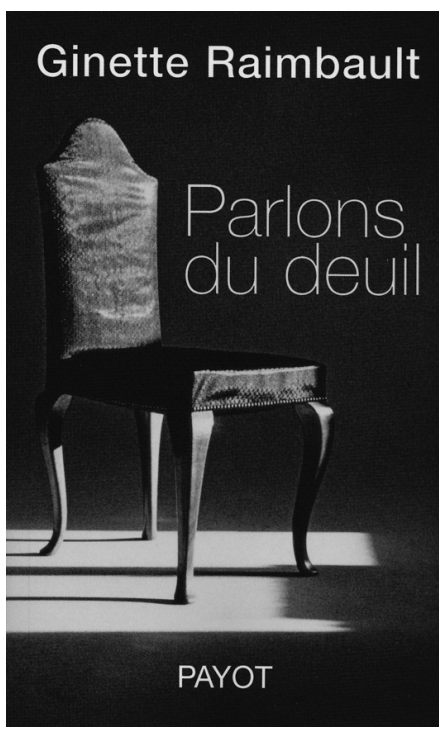

Rédigé par une psychanalyste, ce livre, qui ne comporte ni introduction ni conclusion, est essentielle- 
ment un recueil de témoignages de personnes endeuillées. Le premier témoignage provient de l'auteure elle-même qui relate les deuils qu'ont dû vivre ses propres ancêtres. La parole est aussi donnée à sa nièce qui a perdu ses parents dans une catastrophe aérienne alors qu'elle n'avait que trois ans et demi. Les origines des autres témoignages sont plutôt variées et couvrent un horizon historique contrasté: les Métamorphoses d'Ovide (deuil de Niobé, fille de Tantale et épouse d'Amphion, le roi de Thèbes), des biographies (deuil de la reine Victoria à la suite de la mort du prince Albert; divers deuils de Hermann Hesse), des travaux non identifiés de psychanalystes (deuil d'une fillette âgée de quatre ans lors du suicide de sa mère), un journal intime (deuil d'une mère qui a perdu son bébé), une lettre (deuil $d$ 'un père et d'une mère qui ont perdu leur fils à la guerre en 1945), des émissions radiophoniques (femmes en deuil d'un enfant mortné, d'un autiste décédé très jeune, d'un adolescent qui s'est suicidé, etc.), un cas clinique provenant peut-être de l'expérience professionnelle de l'auteure (deuil d'un enfant de huit ans lors du suicide de sa mère). L'identification précise de certains témoignages est parfois impossible; c'est par exemple le cas du deuil de cette jeune femme originaire d'Afrique noire qui a perdu son bébé lors de son accouchement dans une maternité en banlieue parisienne. Les nombreux témoignages, qui portent sur le deuil des enfants ou des parents ayant perdu un enfant, permettent à l'auteure de donner quelques conseils et de réfléchir à la représentation de la mort chez les enfants et aux effets sur les endeuillés (surtout les enfants) de la mort d'un proche. Par contre, ces réflexions sont trop rares et proviennent pour l'essentiel de l'œuvre de Sigmund Freud. Qui plus est, les nombreuses citations du fondateur de la psychanalyse ne sont jamais suivies d'une référence précise. Seule la petite bibliographie qui clôt l'ouvrage permet d'identifier les livres de Freud dont s'est fortement inspirée l'auteure. Quant aux autres références de cette courte bibliographie, elles sont pour la plupart incomplètes. En outre, les sources des opinions ou des citations de plusieurs autres auteurs mentionnés dans le livre (par exemple, Dorothy Berlingham, Anna Freud, Donald W. Winnicott, Philippe Ariès, Michael Balint) ne sont aucunement signalées ni en notes ni dans la bibliographie.
En définitive, ce livre est certes émouvant à cause des nombreux témoignages qu'il contient, mais il est aussi décevant parce qu'il manque de rigueur au plan méthodologique et surtout parce qu'il ne donne pas suffisamment de place aux analyses et aux réflexions critiques sur le deuil.

Jean-Jacques Lavoie

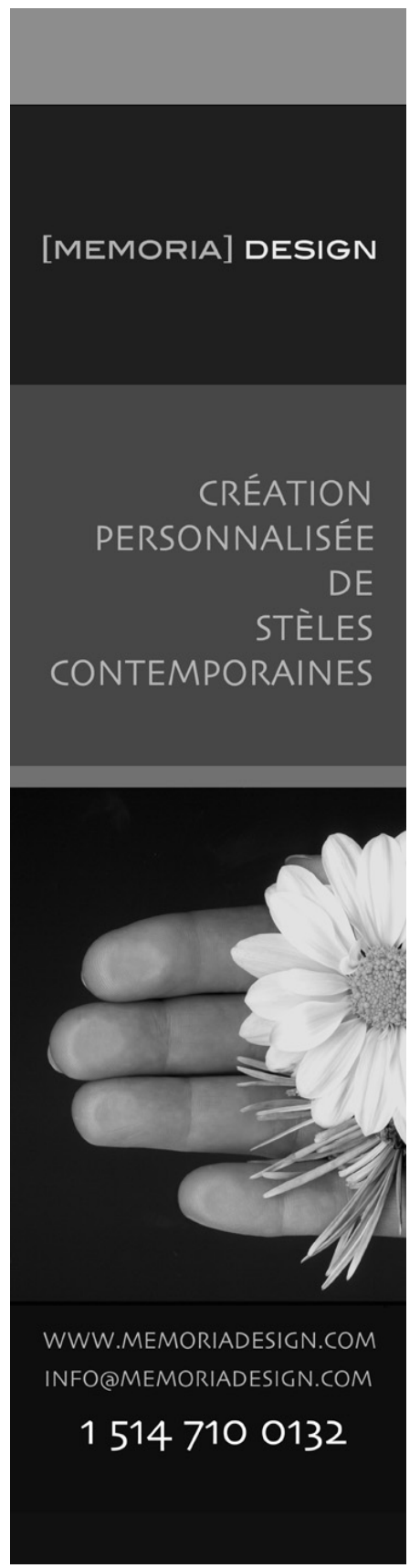

